Original Research Article

\title{
A comparative study of the efficacy of amisulpride and olanzapine in patients with schizophrenia attending the outpatient Department of Psychiatry in a tertiary care hospital, Silchar, Assam, India
}

\author{
Ali N. Yashin ${ }^{1}$, Dolly Roy ${ }^{1 *}$, Prosenjit Ghosh ${ }^{2}$
}

\begin{abstract}
${ }^{1}$ Department of Pharmacology, ${ }^{2}$ Department of Psychiatry, Silchar Medical College and Hospital, Silchar, Assam, India
\end{abstract}

Received: 04 December 2018 Accepted: 29 December 2018

\begin{abstract}
*Correspondence to: Dr. Dolly Roy, Email: drdollyroy20@ gmail.com
\end{abstract}

Copyright: (C) the author(s), publisher and licensee Medip Academy. This is an openaccess article distributed under the terms of the Creative Commons Attribution NonCommercial License, which permits unrestricted noncommercial use, distribution, and reproduction in any medium, provided the original work is properly cited.

\begin{abstract}
Background: Schizophrenia is one of the most commonly encountered psychiatric disorders. It is characterized by impairment in perception or expression of reality, leading to occupational and social dysfunction. Now a day's mainstay of treatment of schizophrenia is by using atypical antipsychotics. Amisulpride and olanzapine are atypical antipsychotics which are commonly used in treatment of schizophrenia. The current study is undertaken to assess the efficacy of amisulpride which is a relatively newer antipsychotics against existing antipsychotic olanzapine.
\end{abstract}

Methods: This was designed as a single-blind, prospective, parallel-group, observational study. Eighty adult patients of either sex were randomized to receive standard doses of the two drugs orally for 12 weeks, with follow up at 4 and 8 weeks. Effectiveness was assessed by change in the score of Brief Psychiatric Rating Scale (BPRS) and Clinical Global Impression (CGI) score during the treatment period. Data were entered in Microsoft excel and statistical analysis were done using graph pad and $\mathrm{p}$ value $<0.05$ considered to be statistically significant.

Results: Out of 80 adults patients 76 patients were evaluated by dividing into two groups, 38 patients were included in each group. Final BPRS score was less for olanzapine as compared to amisulpride $(\mathrm{p}<0.001)$. Improvement in CGI score is more in olanzapine group than amisulpride group which became statistically significant from $8^{\text {th }}$ weeks onwards.

Conclusions: Both amisulpride and olanzapine are very effective in controlling the symptoms of schizophrenia which is evident by significant decrease in BPRS, CGI-S and CGI-I score, but efficacy of amisulpride is still inferior to olanzapine.

Keywords: Amisulpride, Atypical antipsychotics, Olanzapine, Schizophrenia

\section{INTRODUCTION}

Psychiatric disorders are characterized by disturbances in emotion, cognition, motivation and also socialization. In today's world there is a very high prevalence of mental disorders which increases the burden of illness worldwide. Diagnosis of psychiatric disorders are made exclusively from clinical observation using criteria in the Diagnostic and Statistical Manual of Mental Disorders of the American Psychiatric Association (2000), $4^{\text {th }}$ edition, text revision (DSM-IVTR). ${ }^{1}$ Schizophrenia is among one of the most commonly encountered psychiatric disorders. It is characterized by impairment in perception or expression of reality, leading to occupational and social dysfunction. ${ }^{2}$ Worldwide prevalence of schizophrenia is $1 \%$ with almost equal gender distribution. ${ }^{3}$ Schizophrenia is a chronic recurring psychotic illness that characteristically begins in young adult years and lasts for lifetime. ${ }^{4,5}$ In India there are an estimated four million people living with schizophrenia who are imposing different of impact on some 25 million family members. Schizophrenia exposes those afflicted individuals to higher degree of morbidity and mortality than in seen in general population. 6,7 The use of antipsychotic medication is now universal first-line 
treatment of schizophrenia. The newer atypical antipsychotic drugs are increasingly being preferred over older typical antipsychotic medication for treatment of schizophrenia due to their favourable adverse drug reaction $(\mathrm{ADR})$ profile. $^{8}$

Amisulpride is a substituted benzamide derivative with dopamine receptor antagonist properties in vitro and in vivo. Although in clinical studies its efficacy in the treatment of schizophrenia has been clearly demonstrated, its most notable characteristic is its atypical profile. ${ }^{9}$ Amisulpride was approved for marketing in India on $1^{\text {st }}$ August 2006. ${ }^{10}$

Olanzapine is an atypical antipsychotic introduced in 1996 is now commonly used as first line drug in the treatment of acute symptoms and also for long term maintenance therapy. ${ }^{11}$ Recent studies have shown that olanzapine is likely to induce weight gain and also increase risk for obesity related diseases. ${ }^{12}$ Indeed in USA, olanzapine comes with a specific warning for increased risk of diabetes mellitus. ${ }^{13}$ Studies regarding the efficacy of amisulpride are still very less in India. So, the current study is undertaken to compare the efficacy of amisulpride with olanzapine in patients with schizophrenia.

\section{METHODS}

This was designed as a single-blind, prospective, parallelgroup, observational study carried out in the outpatient department of psychiatry in Silchar Medical College and Hospital. The study protocol conformed to the Declaration of Helsinki (as revised in Edinburgh 2000) and was approved by the ethics committee of Silchar Medical College \& Hospital. Written informed consent was taken from each participant. Illiterate patients gave their fingerprint (left thumb impression) instead of signature in presence of appropriate witness. Total duration of study was 12 months (From June 2017 to June 2018).

Sample size involved 40 evaluable patients in each group or total 80 patients. This was estimated to detect a difference, between groups, of 6 in Brief Psychiatric Rating Scale (BPRS) score, with $80 \%$ power and $5 \%$ probability of Type I error.

\section{Inclusion criteria}

- All patients diagnosed with schizophrenia according to ICD-10 criteria between 18-50years age group of either sex,

- Patients with normal blood haemogram, normal blood sugar level, normal lipid profile, normal ECG,

- Patients already on any other antipsychotic medications but with a history of drug free period of 6 weeks.

\section{- Exclusion criteria}

- Pregnant and lactating woman,
- Patients with severe psychosis and violent behaviour,

- Patients having immunosuppression due to drug or disease,

- Patients with significant disease of vital organs, adrenal or pituitary gland.,

- Those receiving medication which prolong QT interval on ECG or capable of otherwise interacting with study medications and,

- Patient unable or not willing to give consent.

Randomization was done in blocks of 10 by computergenerated random number list. The treatment duration was 12 weeks following randomization, with follow-up visits were scheduled at 4 weeks and 8 weeks. Each recruited subject received either amisulpride (400mg total daily dose) administered as a single oral daily dose or olanzapine (10mg total daily dose) administered once daily orally. The starting dose was decided by the concerned clinician, depending on the severity of illness. Up titration, if needed, was permitted only once during the course of the study. The medications were supplied by hospital and were dispensed free-of-cost to the patients.

Primary effectiveness was assessed by decrease in BPRS14 score over 12 weeks period. Secondary effectiveness was assessed by Clinical global Impression (CGI) score by physician. ${ }^{15-17}$

\section{Statistical analysis}

Collected data were entered in computer database with the help of Microsoft excel-2007 and analysis was done in the department of pharmacology, Silchar Medical College and Hospital, Silchar. Statistical analysis was done using parametric and non-parametric test. ' $p$ ' value $\leq 0.05$ was considered to be significant.

\section{RESULTS}

A total 85 patients were screened for the study who attended the outpatient Department of Psychiatry of Silchar Medical College and Hospital and diagnosed as case of schizophrenia. Among them 80 (94\%) patients were recruited for the study and 5 patients were excluded since they did not meet the inclusion criteria. Those 80 patients were divided randomly into 2 groups: 40 each. Of these 4 patients were lost to follow up, 2 from each group. Remaining 76 patients were analysed for different parameters as mentioned in the methodology, 38 patients in amisulpride group and 38 in olanzapine group.

\section{Socio-demographic profile}

Out of 76 patients, $46(60.5 \%)$ were male and $30(39.5 \%)$ were female. The most commonly involved age group was 41 -50years (27 patients). A gender wise and age wise distribution of patients in two drug groups are summarized in Figure 1. 


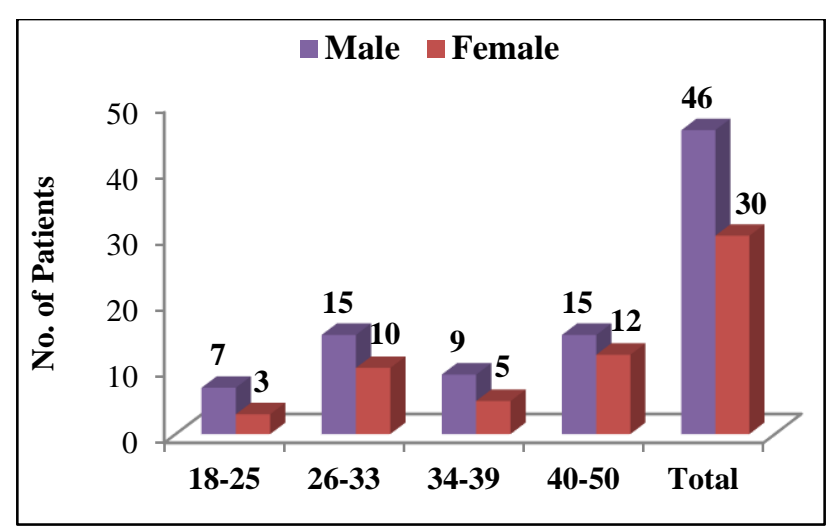

Figure 1: Distribution of cases according to sex and age.

\section{Clinical efficacy of drugs under study}

Table 1: Change in BPRS score over 12 weeks.

\begin{tabular}{|lll|l|}
\hline BPRS & $\begin{array}{l}\text { Amisulpride } \\
(\mathbf{n}=38)\end{array}$ & $\begin{array}{l}\text { Olanzapine } \\
(\mathbf{n}=38)\end{array}$ & $\begin{array}{l}\text { p value } \\
\text { (between } \\
\text { groups) }\end{array}$ \\
\hline Baseline & $62.89 \pm 3.35$ & $61.74 \pm 3.73$ & 0.158 \\
\hline $4^{\text {th }}$ week & $52.03 \pm 4.16$ & $53.07 \pm 4.16$ & 0.299 \\
\hline $8^{\text {th }}$ week & $41.58 \pm 2.71$ & $40 \pm 3.88$ & 0.043 \\
\hline $\begin{array}{l}12^{\text {th }} \\
\text { week }\end{array}$ & $30.21 \pm 2.17$ & $28.09 \pm 2.13$ & $<0.001$ \\
\hline $\begin{array}{l}\text { p value } \\
\text { (within } \\
\text { groups) }\end{array}$ & $<0.001$ & $<0.001$ & - \\
\hline Valus & & $<$ & \\
\hline
\end{tabular}

Values are mean $\pm \mathrm{SD} ; \mathrm{p}$ value between the groups is by unpaired $t$ test whereas within group is by repeated measure ANNOVA with Bonferroni multiple comparison test.

The change in BPRS score are depicted in Table 1. It was seen that there was a gradual decrease in of BPRS score in both the groups over the study period. When this was compared within the groups the decrease in BPRS score was found to be statistically significant $(p<0.001)$ in both the treatment arms. When change in BPRS was compared in between the groups, there were no statistically significant difference seen in baseline and 4th week, but BPRS score became statistically significant at 8th week and at the end of study $(\mathrm{p}<0.05)$.

\section{Change in the Clinical Global Impression score for severity of illness (CGI-S)}

The change in CGI-S score are shown in Table 2. From the table and figure it was obvious that CGI-S score was decreasing in both the treatment groups over 12 weeks periods. The decrease is statistically significant $(\mathrm{p}<0.001)$ when compared between the visits in both study groups. When between group comparison was done, both the groups were comparable till $4^{\text {th }}$ week but from $8^{\text {th }}$ week onwards statistically significant difference $(p<0.05)$ were noted between both the study groups.
Table 2: Change in CGI-S score over 12 weeks.

\begin{tabular}{|lll|l|}
\hline CGI-S & $\begin{array}{l}\text { Amisulpride } \\
(\mathbf{n = 3 8})\end{array}$ & $\begin{array}{l}\text { Olanzapine } \\
(\mathbf{n = 3 8})\end{array}$ & $\begin{array}{l}\text { p value } \\
\text { (between } \\
\text { groups) }\end{array}$ \\
\hline Baseline & $5.29 \pm 0.46$ & $5.26 \pm 0.45$ & 0.804 \\
\hline $4^{\text {th }}$ week & $4.24 \pm 0.43$ & $4.18 \pm 0.39$ & 0.581 \\
\hline $8^{\text {th }}$ week & $3.16 \pm 0.36$ & $2.97 \pm 0.37$ & 0.036 \\
\hline $12^{\text {th }}$ week & $2.26 \pm 0.04$ & $1.89 \pm 0.56$ & 0.003 \\
\hline p value & $<0.001$ & $<0.001$ & - \\
\hline
\end{tabular}

Values are mean $\pm \mathrm{SD} ; \mathrm{p}$ value between the groups is by unpaired $t$ test whereas within group is by repeated measure ANNOVA with Bonferroni multiple comparison test.

\section{Change in the Clinical Global Impression score for global improvement (CGI-I)}

The CGI-I score was not assessed at baseline visit. Change in CGI-I score over the treatment period was depicted in Table 3. CGI-I score decreased gradually during the study period in both the treatment groups. When compared between different visits, the decrease of CGI-I score was found to be statistically significant in both groups. When intergroup comparison was done, both the groups were comparable at $4^{\text {th }}$ and $8^{\text {th }}$ week but statistically significant difference $(\mathrm{p}<0.001)$ was seen at $12^{\text {th }}$ week.

Table 3: Change in CGI-I score over 12 weeks.

\begin{tabular}{|lll|l|}
\hline CGI-I & $\begin{array}{l}\text { Amisulpride } \\
(\mathbf{n = 3 8})\end{array}$ & $\begin{array}{l}\text { Olanzapine } \\
(\mathbf{n = 3 8})\end{array}$ & $\begin{array}{l}\text { p value } \\
\text { (between } \\
\text { groups })\end{array}$ \\
\hline Baseline & 0 & 0 & 0 \\
\hline $4^{\text {th }}$ week & $4.29 \pm 0.46$ & $4.21 \pm 0.41$ & 0.433 \\
\hline $8^{\text {th }}$ week & $2.96 \pm 0.23$ & $2.92 \pm 0.27$ & 0.654 \\
\hline $12^{\text {th }}$ week & $2.11 \pm 0.39$ & $1.66 \pm 0.49$ & $<0.001$ \\
\hline p value & $<0.001$ & $<0.001$ & - \\
\hline
\end{tabular}

Values are mean $\pm \mathrm{SD} ; \mathrm{p}$ value between the groups is by unpaired $t$ test whereas within group is by repeated measure ANNOVA with Bonferroni multiple comparison test.

\section{DISCUSSION}

Present study showed that most of the patients were in the age group of 40-50years with greater incidence in male than female. However, the study conducted by Bhowmik $S$ et al, Martin et al, and Power et al, showed that incidence of schizophrenia was more in thirties which was in contrast to present study. ${ }^{18-20}$ This difference could be due small sample size of our study, which did not reflect actual disease burden in the population. In present study it was found that schizophrenic illness is more common in males $46(60.5 \%)$ compared to females 30 (39.5\%). Similar type of studies done by Bhowmik S et al, and Pawar et al, showed male patients were $40(52 \%)$ and $35(54.7 \%)$ and female were $38(48 \%)$ and $27(45.3 \%)$ respectively. ${ }^{18,20}$

In present study the primary effectiveness variable used was Brief Psychiatric Rating Scale (BPRS) scale. ${ }^{14}$ This scale describes the patient condition by evaluating different 
positive and negative symptoms. This BPRS scale is actually a shorter version of Positive and Negative Syndrome Scale (PANSS). ${ }^{21}$ Present study showed that there was improvement in BPRS score both in amisulpride group and olanzapine group, but this improvement became significant from $2^{\text {nd }}$ follow up onwards. Overall improvement was more in olanzapine than amisulpride. Also, the scores decreased significantly from baseline to the end follow up visit in both the study groups. This showed that both the drugs were quite effective in treating the symptoms of schizophrenia. But olanzapine seemed to be more effective than amisulpride in our study. It was observed that there were rapid decrease in BPRS after $4^{\text {th }}$ week in both the groups favouring the use of both the drugs in treating schizophrenia.

When secondary effectiveness variables were considered, in the present study it was seen that there were significant ( $p<0.001)$ decrease in the Clinical Global Impression severity scale (CGI-S) and Clinical Global Impression Improvement scale (CGI-I), from baseline till end follow up in both the study groups and this decrease was more in case of olanzapine than amisulpride when both groups were compared to each other and became statistically significant at $8^{\text {th }}$ and $12^{\text {th }}$ week in case of CGI-S whereas statistical significance was seen only in end follow up visit in case of CGI-I. ${ }^{15-17}$

A randomized control trial was conducted by Martin et al ${ }^{19}$ in 2002 known as 'SOLIANOL' study, where they compared the efficacy and tolerability of amisulpride and olanzapine at 2 months. ${ }^{19}$ Mortimer A et al, compared the same results at 6 months. ${ }^{22}$ The 2 months result showed that that amisulpride was at least as effective as olanzapine at improving psychotic symptoms; the total BPRS score fell by $17.6($ S.D.=13.9) points in the amisulpride group and by 16.3 (S.D.=13.4) points in the olanzapine group. After six months the improvement of BPRS score was $32.7 \%$ in the amisulpride group and $33.0 \%$ in the olanzapine group; thus, the efficacy of amisulpride is equal to that of olanzapine. All other secondary efficacy outcome variables evolved to a similar extent in both groups. The authors concluded that the efficacy of amisulpride is not inferior to that of olanzapine in the treatment of acute schizophrenia. Our present study also reflected that change in BPRS score were not statistically significant between two treatment arms at 2 months, but at the end of $3^{\text {rd }}$ month the decrease in BPRS is more for olanzapine than amisulpride which was in agreement with the result obtained by Mortimer A. et al, Lecrubier Y et al, conducted a study in France that compared amisulpride with olanzapine in controlling the negative symptoms of schizophrenia. ${ }^{22,23}$ Here, olanzapine showed significantly greater improvement than placebo and amisulpride in the positive and negative symptom scales total scores. Similiar results were obtained by Haro JM et al, where they conducted a study on more than 10970 patients from 10 European countries, who were initiating or changing antipsychotic medication for the treatment of schizophrenia, were studied for 3 years. ${ }^{24}$ The patients treated with olanzapine and clozapine tended to have somewhat better outcomes than patients treated with other atypical or typical antipsychotics. That study also showed that olanzapine reduced the positive and negative symptoms of schizophrenia better than amisulpride. Pawar GR et al, conducted an 8 weeks double blind trial between efficacy and safety of amisulpride and olanzapine. ${ }^{20} 81$ patients were recruited in the study in a single blind manner and allotted either of the study medication. Efficacy was assessed by BPRS score and PANSS scale. During the study period change observed in BPRS score in amisulpride group was 16.80 (SD: 3.61) and in olanzapine group was 15.30 (SD: 2.69). This improvement was similar in both groups and was not statistically significant $(\mathrm{P}=$ 0.38). The results of these studies were similar to that of our one.

Limitations of the present study includes; sample size was small. It was also not possible to get a larger amount of newly diagnosed schizophrenic patients in a year; so it needs a longer duration of time to get a large amount of sample. A larger sample size may have shown clear statistical difference. The treatment period in this study was relatively short (12 weeks), and hence provided no scope for assessing comparative effectiveness of long-term therapy. Another limitation, common to all clinical studies in countries like India is socio-economic status as well as low education of the patients. Improper hygiene, lower nutritional status, and social discriminating factors specially in psychiatric patients along with poor communications with the patients leads to missed follow up and increase amount of non-adherence cases with the treatment protocol. All these factors eventually lead not only to decrease the therapeutic response but also increase the susceptibility of exaggeration of illness and broader spectrum of adverse drug reactions

\section{CONCLUSION}

In conclusion, from our study we can say that amisulpride is very effective in controlling the symptoms of schizophrenia which is evident by significant decrease in BPRS, CGI-S and CGI-I score, but it's efficacy is still inferior to olanzapine.

\section{ACKNOWLEDGEMENTS}

Authors would like to express their sincere gratitude to all respondents for their participation.

Funding: No funding sources Conflict of interest: None declared

Ethical approval: The study was approved by the Institutional Ethics Committee

\section{REFERENCES}

1. American Psychiatric Association. Diagnostic and statistical manual of mental disorders, 4th ed. Washington DC: American Psychiatric Association; 2000 . 
2. Reus VI. Mental disorders. In: Kasper DL, Fauci AS, Longo DL, Braunwald E, Hauser SL, Jameson JL, eds. Harrisons's principle of internal medicine, 16th ed. New York: McGraw-Hill, 2005:2559-60.

3. Messias E, Mourao C, Maia J, Campos JP, Ribeiro K, Ribeiro L, et al. Season of birth and schizophrenia in Northeast Brazil: relationship to rainfall. J Nerve Ment Dis. 2006;194(11):870-3.

4. Carpenter WT. Jr, Buchanan RW. Schizophrenia. N Engl J Med. 1994;330(10):681-90.

5. Tamminga CA, Thakar GK, Medoff DR. Neuropsychiatric Aspects of schizophrenia. Textbook of Neuropsychopharmacology, 4th ed. Washington DC: American Psychiatric Press, 2001.

6. Harris EC, Barraclough B. Excess mortality of mental disorder. Br J Psychiatry. 1998 Jul 1;173(1):11-53.

7. Brown S. Excess mortality of schizophrenia. A metaanalysis. Br J Psychiatry. 1997 Dec 1;171(6):502-8.

8. Lieberman JA. Clinical Antipsychotic Trials of Intervention Effectiveness (CATIE) Investigators; Effectiveness of antipsychotic drugs in patients with chronic schizophrenia. N Engl J Med. 2005;353:120923.

9. Schoemaker H, Claustre Y, Fage D, Rouquier L, Chergui K, Curet O, et al. Neurochemical characteristics of amisulpride, an atypical dopamine D2/D3 receptor antagonist with both presynaptic and limbic selectivity. Journal of Pharmacology and Experimental Therapeutics. 1997 Jan 1;280(1):83-97.

10. Central Drugs Standard Control Organization. New drug approvals in India in 2006 (monograph on the internet). New Delhi: Central Drugs Standard Control Organization; 2006. Available at: http://cdsco.nic.in/new_drugs_app6.html.

11. Thomas S, editor. Drug reference for FDA approved psychiatric drugs (monograph on the internet). Quincy, Illinois: Neurotransmitter.net; 2009. Available at: http://www.neurotransmitter.net/drug reference.html.

12. Cerit C, Vural M, Bos Gelmez SU, Ozten E, Aker AT, et al. Metabolic syndrome with different antipsychotics: a multicentre cross-sectional study. Psychopharmacol Bull. 2010 Jan 1;43(4):22-36.

13. US Food and Drug Administration. 2004 safety alert on Zyprexa (olanzapine). Rockville, MD: US Food and Drug Administration Med Watch Programme, 2004. Available at: http://www.fda.gov/med Watch/ SAFETY/2004/zyprexa.htm.

14. Overall JE, Gorham DR. The brief psychiatric rating scale. Psychol Rep 1962;10:799-812.

15. Leon AC, Shear MK, Klerman GL, Portera L, Rosenbaum JF, Goldenberg I. A comparison of symptom determinants of patient and clinician global ratings in patients with panic disorder and depression. J Clin Psychopharmacol. 1993;13(5):327-3

16. Spearing MK, Post RM, Leverich GS, Brandt D, Nolen W. Modification of the clinical Global Impression (CGI) scale for use in bipolar illness (BP): the CGI-BP. Psychiatry Res. 1997;73(3):159-71.

17. Zaider TI, Heimberg RG, Fresco DM, Schneier FR, Liebowitz MR. Evaluation of the clinical global impression scale among individuals with social anxiety disorder. Psychol Med. 2003 May;33(4):61122.

18. Bhowmick S, Hazra A, Ghosh M. Amisulpride versus olanzapine in the treatment of schizophrenia in Indian patients: randomized controlled trial. Australian New Zealand J Psychiatry. 2010 Jan 1;44(3):237-42.

19. Martin S, Loo H, Peuskens J, Thirumalai S, Giudicelli A, Fleurot O, et al. SOLIANOL Study Group: A double-blind, randomized comparative trial of amisulpride versus olanzapine in the treatment of schizophrenia: Short-term results at two months. Curr Med Res Opin. 2002;18(6):355-62.

20. Pawar GR, Phadnis P, Paliwal A. Evaluation of efficacy, safety, and cognitive profile of amisulpride per se and its comparison with olanzapine in newly diagnosed schizophrenic patients in an 8-Week, double-blind, single-centre, prospective clinical trial. ISRN Psychiatry. 2012 Mar 14;2012.

21. Kay SR, Fiszbein A, Opler LA. The positive and negative syndrome scale (PANSS) for schizophrenia. Schizophrenia Bull. 1987 Jan 1;13(2):261-76.

22. Mortimer A, Martin S, Lôo H, Peuskens J. A doubleblind, randomized comparative trial of amisulpride versus olanzapine for 6 months in the treatment of schizophrenia. Int Clin Psychopharmacol. 2004 Mar 1;19(2):63-9.

23. Lecrubier Y, Quintin P, Bouhassira M, Perrin E, Lancrenon $\mathrm{S}$. The treatment of negative symptoms and deficit states of chronic schizophrenia: olanzapine compared to amisulpride and placebo in a 6-month double-blind controlled clinical trial. Acta Psychiatr Scand. 2006 Nov;114(5):319-27.

24. Haro JM, Salvador-Carulla L. The SOHO (Schizophrenia Outpatient Health Outcome) Study. CNS Drugs. 2006 Apr 1;20(4):293-301.

Cite this article as: Yashin AN, Roy D, Ghosh P. A comparative study of the efficacy of amisulpride and olanzapine in patients with schizophrenia attending the outpatient Department of Psychiatry in a tertiary care hospital, Silchar, Assam, India. Int J Basic Clin Pharmacol 2019;8:284-8. 